\title{
Intelligent Operation of Wheel Loader Based on Electrohydraulic Proportional Control
}

\author{
Bing-wei Cao $\left(\mathbb{D}\right.$, Xin-hui Liu, Wei Chen $\mathbb{D}^{D}$, Peng Tan, and Ping-fang Niu (iD \\ School of Mechanical and Aerospace Engineering, Jilin University, Changchun 130022, China \\ Correspondence should be addressed to Wei Chen; chenwei_1979@jlu.edu.cn
}

Received 23 November 2019; Accepted 30 March 2020; Published 25 April 2020

Guest Editor: Mohamed Nayel

Copyright $\odot 2020$ Bing-wei Cao et al. This is an open access article distributed under the Creative Commons Attribution License, which permits unrestricted use, distribution, and reproduction in any medium, provided the original work is properly cited.

\begin{abstract}
In this paper, the wheel loader with electrohydraulic proportional control technology is used as the carrier. For the first time, the dual-angle sensor is used for intelligent operation, which allows the wheel loader working device to be precisely controlled. First, the theoretical analysis of the electrohydraulic proportional control technology on the wheel loader studied in this paper is carried out. Next, according to the feedback of the boom and bucket angle sensor signals, the electrohydraulic proportional control technology is used to initially realize the boom memory and bucket automatic levelling function of the wheel loader working device. Finally, the data acquisition equipment is connected to provide experimental verification, although the test results did not achieve precise control of the working device. After analysis, the detected problems were solved by constructing a neural network algorithm model, which successfully realizes the intelligent and precise operation of the wheel loader, reducing unnecessary energy loss.
\end{abstract}

\section{Introduction}

As the main type of groundwork construction equipment in a project, the wheel loader has the advantages of fast operational speed, high efficiency, good manoeuvrability, and light operation [1]. The application of electrohydraulic proportional control technology further enhances the intelligence of the wheel loader operation, reduces the driver's operational intensity, and provides an application platform for other advanced technologies [2-4].

Electrohydraulic proportional control technology has been successfully applied in wheel loader power, transmission, hydraulic, cooling, and other systems. In recent years, there have been many studies on electrohydraulic proportional control [5-8]. Bing et al. used the electrohydraulic load sensitive method of variable pressure margin to control the displacement of variable pump and realized the energy-saving control of the combined control system of pump and valve [9]. Yongling studied the defects of poor stability and low control precision, in real operational conditions, of the electromechanical liquid proportional control system. The electrohydraulic proportional control method, based on PWM technology, is proposed [10]. Based on the working principle of electrohydraulic proportional directional valve, Zhang et al. tested the electrohydraulic proportional position control approach. They then built a valve control cylinder test bench, realizing precise control of hydraulic cylinder position [11]. Fang et al. started with the classic PID control method, along with fuzzy control approach, and adopted the intelligent fuzzy-PID collaborative control strategy, achieving higher system control precision [12]. Although the electrohydraulic proportional control technology has been successfully applied to the wheel loader, it has not been found that the angle sensor is used as a feedback signal to realize the boom memory and the bucket automatic levelling function of the wheel loader. The realization of the above functions can assist the driver to complete the operation of the wheel loader, that is, to realize intelligent operation; this is also the innovation of this paper. The application of the above proportional control technology provides a platform for implementing the function in this paper.

The wheel loader, studied in this paper, successfully applied the electrohydraulic proportional control 
technology to realize the control of the working hydraulic system. However, when the boom memory and the bucket automatic levelling function were realized, the control precision proved to be poor and did not reach the expected target. Therefore, this paper successfully applied the neural network algorithm to the intelligent operation of the wheel loader and achieved the precise control of the working device.

Neural networks have infinite approximation ability to nonlinear models, while they have been widely used as tools for building nonlinear models [13-15]. By adjusting the weight of the connected network, any input can be made to obtain the desired output [16-18]. Xu and Mai designed and utilized the supervised neural network learning algorithm to deal with the problem of low precision and system instability during the operation of hydraulic material testing machine. The study results show that the neural network control optimized electrohydraulic position servo system demonstrates better stability and robustness [19]. Ni et al. combined the BP network with the traditional PID controller to monitor the actual value and set and error values of the slider at different times in real time while using the online selflearning ability of the neural network to realize the optimal combination of PID parameters. Accurate slider displacement control and simulation curves also prove that BP neural network is very effective in improving hydraulic servo control [20]. Gao and Han, in order to solve the coupling problem of hydraulic four-legged robot joints, established a single-legged mechanism for the hydraulic four-legged robot. In this work, based on the multivariable decoupling theory, the neural network (NN) model reference decoupling controller is designed [21]. The successful application of the neural network algorithm described above in the hydraulic system provides a prerequisite for the intelligent operation of the wheel loader working device.

The wheel loader, studied in this paper, uses electrohydraulic proportional control technology as an application platform. For the first time, the dual-angle sensor is used, combined with the typical V-type working cycle of the wheel loader, to realize the boom memory and bucket automatic levelling function of the working device. In addition, theoretical analysis of the electrohydraulic proportional control technology is used in the wheel loader. Signals, such as cylinder pressure, sensor angle, handle voltage, and engine speed are acquired and recorded, through the connected data acquisition device. The data curve shows that the working device is not accurately controlled, while the actual stopping angle of the boom is always greater than the memory angle of the hydraulic system controller. After analyzing the reasons, the neural network algorithm is applied to optimize, followed by a test verification of the results. The experiment showed that the neural network algorithm can be used for intelligent and precise control of the wheel loader working device, reducing unnecessary energy loss.

\section{Electrohydraulic Proportional Control Technology}

Figure 1 shows the evolution of the control mode of the wheel loader working device. Figure 1(a) shows the most primitive form of control. The spool movement is controlled by a flexible shaft. Figure 1(b) shows the movement of the spool controlled by the pilot oil pressure. The handle is equivalent to a pressure reducing valve, and the pilot pressure corresponds to the displacement of the spool. Figure 1(c) shows the control of spool movement through an electromagnetic proportional pressure reducing valve, currently the most advanced type of control. The wheel loader designed in this paper also adopts this control method.

The principle of electrohydraulic proportional control technology applied to this wheel loader is as follows: the control handle is used as a signal generator to supply the required controlled voltage to the controller. Then, it performs a corresponding operation and supplies output current to the electromagnetic proportional pressure reducing valve, according to the front-end signal and completes control of the hydraulic cylinder of the working device after the main reversing valve. Figure 2 shows the schematic diagram of the electrohydraulic proportional control hydraulic system of the working device.

The control handle is divided into a boom handle and a bucket handle. The handle is single axis and is equipped with an electromagnetic stop function. The structure is a springreturned, dual-sensor device, providing an output voltage of $0.5 \sim 4.5 \mathrm{~V}$. The electrical characteristics of the handle are shown in Figure $3[22,23]$.

$$
U=K_{l} \cdot \theta,
$$

where $K_{l}$ is the handle scale factor and $\theta$ is the handle action angle, with a range of $-20^{\circ} \leq \theta \leq 20^{\circ}$.

After the analogy voltage signal output, by the handle, the voltage signal is input to the hydraulic system controller, and the controller outputs the corresponding current signal to the electromagnetic proportional pressure reducing valve according to the voltage signal, where the output is $I$ [24]:

$$
I=K_{a} U
$$

where $K_{a}$ is the voltage-current gain of the controller, which is set as 0.215 .

The main control valve uses electrohydraulic remote control, while the proportional pressure reducing valve is integrated with the main valve. After receiving the current signal, the electromagnetic proportional pressure reducing valve on the main valve realizes the control of the direction and flow of the main control oil passage and then controls the movement direction and speed of the wheel loader working device. The turn-on current is $300 \mathrm{~mA}$, and the final current is $500 \mathrm{~mA}$. The main control valve uses an internal oil circuit in parallel form, which can realize the joint operation of the boom and the bucket.

Since the conventional wheel loader does not have a hydraulic system controller, unable to accept the signal from the angle sensor, the wheel loader operation needs to be 


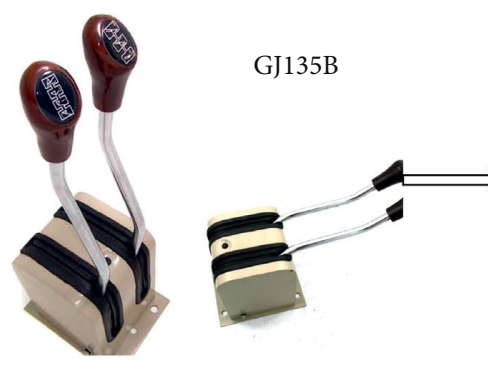

(a)

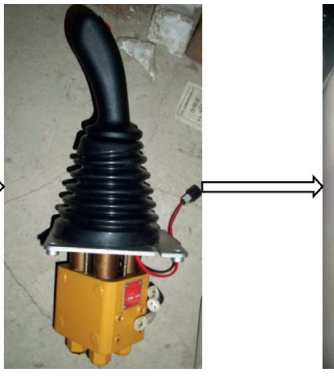

(b)

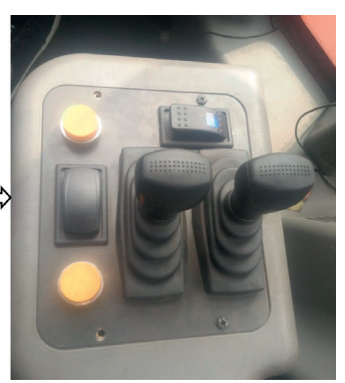

(c)

Figure 1: The evolution of control mode of the wheel loader. (a) Flexible shaft. (b) Hydraulic control. (c) Electrohydraulic proportional control.

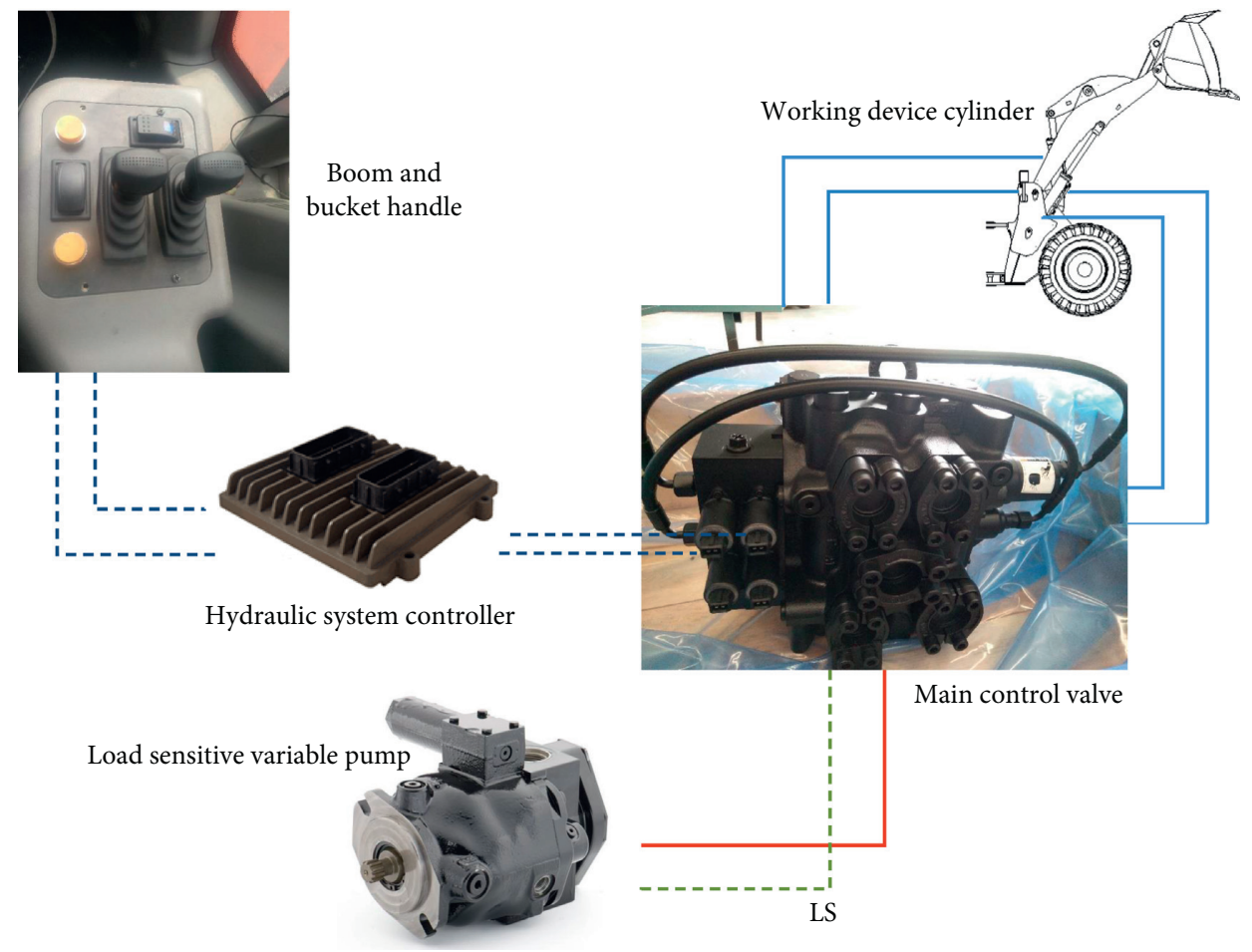

FIGURE 2: Electrohydraulic proportional control hydraulic system.

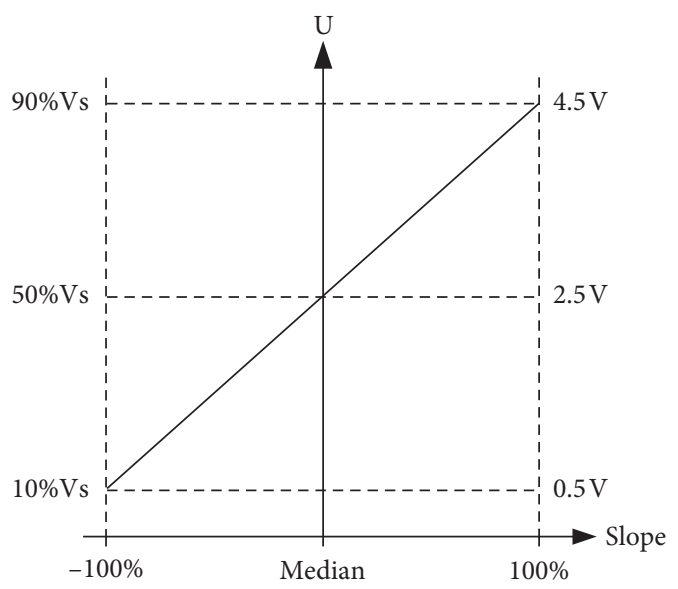

FIGURE 3: Handle electrical characteristics. manually controlled by the driver, so the boom memory and the bucket automatic levelling function cannot be realized. The most used switch is the limit switch, but the limit switch can only remember one position. Real-time monitoring of the angle of the loader's working device can be achieved by installing an angle sensor in the appropriate position, combined with a hydraulic system controller. The following describes the intelligent working mechanism of the wheel loader.

\section{Intelligent Operation}

The V-type working mode of the wheel loader has the characteristics of wide adaptability and short working cycle time [25]. The working cycle of the V-type working mode is shown in Figure $4[26,27]$. The intelligent operation of the so-called 


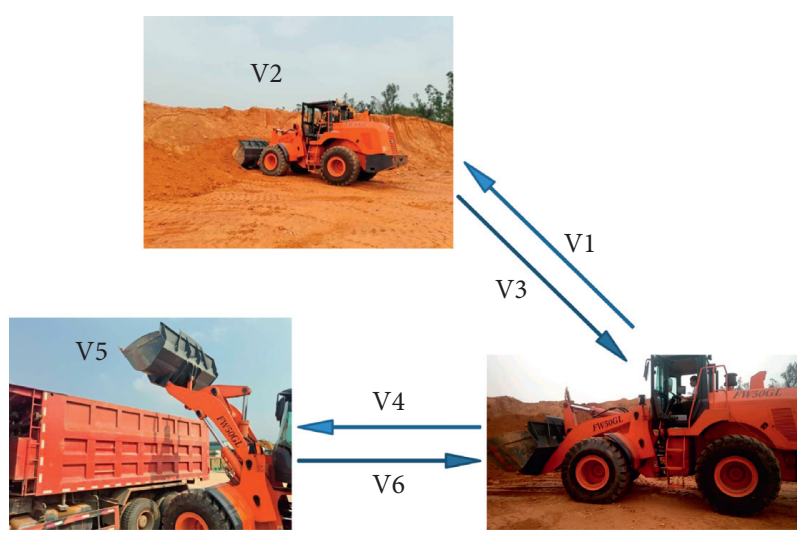

Figure 4: Wheel loader V-type work cycle.

wheel loader working device is to assist the driver to complete related operations through the hydraulic system controller, thereby reducing the labour intensity of the driver. The following describes the intelligent operation of the working device in detail with the $\mathrm{V}$-shaped cycle of the wheel loader.

During the V3 and V4, the driver needs to operate the boom handle to raise the working device to the discharge height. When the discharge position is reached, the driver operates the bucket handle to perform the unloading operation. After unloading, the bucket needs to be recovered to prevent it from colliding with the truck box and be ready for the next shovel operation. During the V6 and V1, the driver operates the boom handle to lower the boom. When the boom is lowered, the bucket needs to be adjusted to a flat position, which is beneficial for the shovel loading operation.

During a V-type cycle operation, since the type of the truck does not have a large gap, the height reached by the wheel loader is constant each time. In order to facilitate the next shovel loading operation, the bucket should be levelled, when it falls on the ground. Therefore, in the entire $\mathrm{V}$-shaped cycle, the driver needs to frequently operate the boom and the bucket handle to adjust the posture of the working device [25]. In order to reduce the driver's operation involvement, this research group and a company worked together to develop a $5 t$ wheel loader, as a prototype. The function diagram of the boom memory and the bucket automatic levelling is shown in Figure 5. For the first time, two angle sensors are used to measure the angle of the boom and bucket in real time to realize the boom memory and bucket automatic levelling function of the wheel loader working device. The functional flowchart is shown in Figure 6 . The handle outputs a voltage signal to the hydraulic system controller, which ranges from 0.5 volts to 4.5 volts. In the hydraulic system controller, the voltage signal is converted to the percentage of handle opening. 0.5 2.5 corresponds to $0 \sim 100 \%$, and $2.5 \sim 4.5$ corresponds to $-100 \sim 0 \%$. The control current of the proportional solenoid's valve is $300 \sim 730 \mathrm{~mA}$. It is one-to-one correspondence between the percentage of signal and control current signal. Therefore, the handle opening signal is converted into current signal in the hydraulic controller.

As the wheel loader performs the loading operation, after the boom is lifted to the discharge height, the driver presses

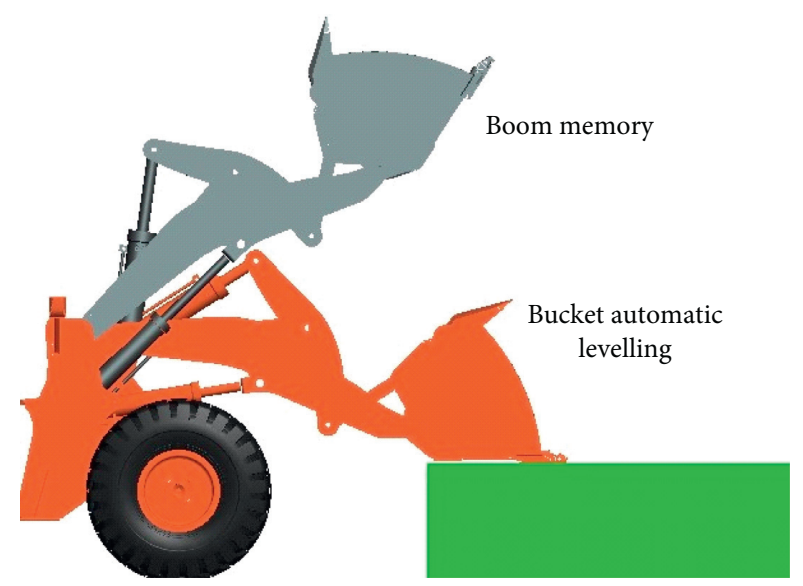

FIgURE 5: Function diagram.

the boom memory switch, so that the hydraulic system controller saves the angle of the boom angle sensor. At this boom angle, there is a unique bucket angle value, corresponding to the automatic levelling function of the bucket. The automatic levelling angle of the bucket corresponding to different boom heights is different, but the two angle values are one-to-one correspondence. The aforementioned angle is input to the hydraulic system controller, as data in a table, derived from the ADAMS model of the working device. Next, the driver operates the bucket handle to unload the material, and the bucket is required to retract after unloading. Currently, the bucket handle is in the suction state under the action of electromagnet. When the angle monitored by the bucket angle sensor corresponds to the angle in the data table, the electromagnet of the bucket handle is powered off. The handle is in the middle position. The bucket is levelled, when the working device is placed on the ground. After the hydraulic system controller has memorized the boom angle, next time the boom is lifted, the electromagnet of the boom handle is in the suction state. As the boom memory angle is reached, the electromagnet is powered off and the handle is in the middle position. At this time, the height of the working device is the same as the height set by the driver. In the above operation, under the action of the hydraulic system controller, the boom memory of the wheel loader and the automatic levelling function of the bucket are realized, which reduces the operation intensity of the driver.

According to the above analysis, the combination of the angle sensor and the electrohydraulic proportional control technology can assist the driver to complete the boom raising and the bucket levelling operation. The function described above is the intelligent operation of the wheel loader; the following is an experiment to verify the intelligent operation of the wheel loader.

\section{Test Verification}

This section describes the verification of the loading boom memory and the bucket automatic levelling functions, by connecting the data acquisition device. The test data to be collected include the boom and bucket handle voltage 


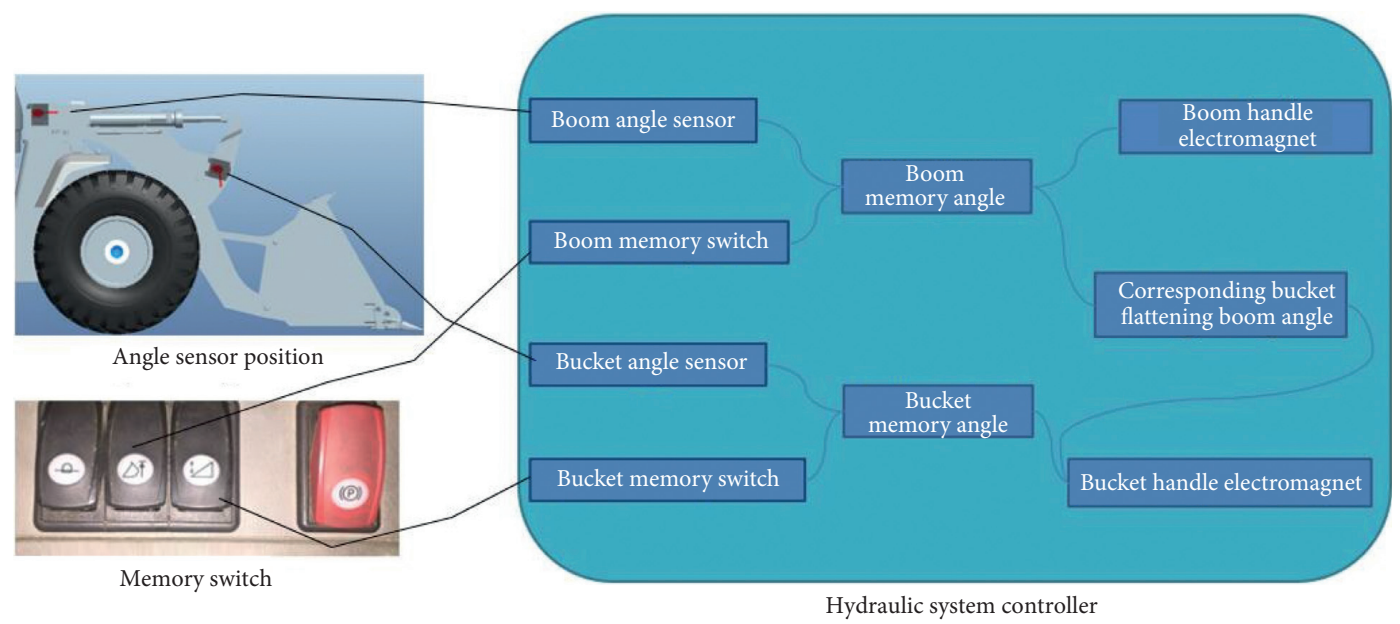

FIGURE 6: Function flowchart.

signals; the boom and bucket pilot pressure signals; the boom and bucket angle sensor signal; and engine speed signal. The test equipment is shown in Figure 7.

After the memory boom angle is $45^{\circ}$, the wheel loader is started, and the boom height memory function is realized by the hydraulic system controller. The engine speed ranges from $800 \mathrm{r} / \mathrm{min}$ to $2200 \mathrm{r} / \mathrm{min}$, while the angle value, during the stop position of the boom, is recorded every $200 \mathrm{r} / \mathrm{min}$, as shown in Table 1 . The actual stop angle curve of the boom, during the verification, is shown in Figure 8.

Figure 8 shows that the actual stop angle of the aforementioned boom becomes larger, as the engine speed increases, while at the maximum speed, it reaches $51.58^{\circ}$, which far exceeds the value $\left(45^{\circ}\right)$ memorized by the hydraulic system controller. The same is true for the bucket angle sensor feedback signal. The above phenomenon causes the actual stop angle of the boom to be higher than the memory angle. The bucket recovery angle is also greater than the memory angle of the hydraulic system controller. Reallife boom memory and bucket automatic levelling cannot be realized. Since the actual stop angle is always greater than the memory angle, this will result in loss of certain amount of power. This angle difference is also meaningless because the memory angle has reached the driver's needs.

During the test, it was also found that as the memory angle in the hydraulic system controller increases, the actual stop angle of the boom also increases. The reciprocating boom memory function is performed at different angles, and the actual stopping angle of the boom at different speeds is measured as shown in Table 2 .

The above tests were carried out under no-load conditions, and it was impossible to carry out the no-load operation when the wheel loader was working. Therefore, the load factor must also be considered. The boom memory function tests with loads of $3 t$ and $5 t$ were also performed, while the actual stop angle of the boom was obtained, as shown in Table 3.

As can be seen from Tables 1-3, the data in the table are the actual stopping angle of the boom obtained according to different engine speeds and different memory angles.
Comparing Tables 1-3, the actual stop angle of the boom when there is load is not much different from the actual stop angle of the boom when there is no load, so the influence of the load on the memory function of the boom can be ignored.

The reasons for the above phenomena are analyzed below. The boom handle voltage signal, pilot pressure signal, and boom angle signal are recorded, as shown in Figure 9. The illustrated graph shows that when the hydraulic system controller cuts off the voltage signal of the boom handle, its value fluctuates, due to the spring inside the handle. As the voltage oscillates, the pilot pressure is not cut off in time, so the main control valve is not closed in time. This is the main reason that causes the boom stop angle to be greater than the hydraulic system controller angle value. As the rotational speed increases, the flow rate, provided by the variable pump, continues to rise, causing the flow, through the main valve, to increase per time unit, leading to the difference increase, as the engine speed rises.

In theory, the dead zone area of the boom handle and the bucket handle should be increased in the hydraulic system controller. However, if the value is too large, the driver's operating experience will be affected, which is not conductive to microaction. Therefore, an optimization algorithm should be considered to realize the function of the boom memory and the bucket automatic levelling.

\section{Algorithm Optimization}

Neural network algorithms have successfully solved many practical problems that are difficult to solve in an intelligent way, in the fields of pattern recognition, automatic control, predictive evaluation, etc [28-31]. In this case, a large amount of data has been obtained from the actual test and input into the neural network algorithm model, while data other than the test data can be predicted, thereby realizing intelligent and precise control of the wheel loader working device. Through experiments on different engine speeds and memory angles, the actual stopping angle of the boom can be obtained. Speed and memory angle are used as the input of 

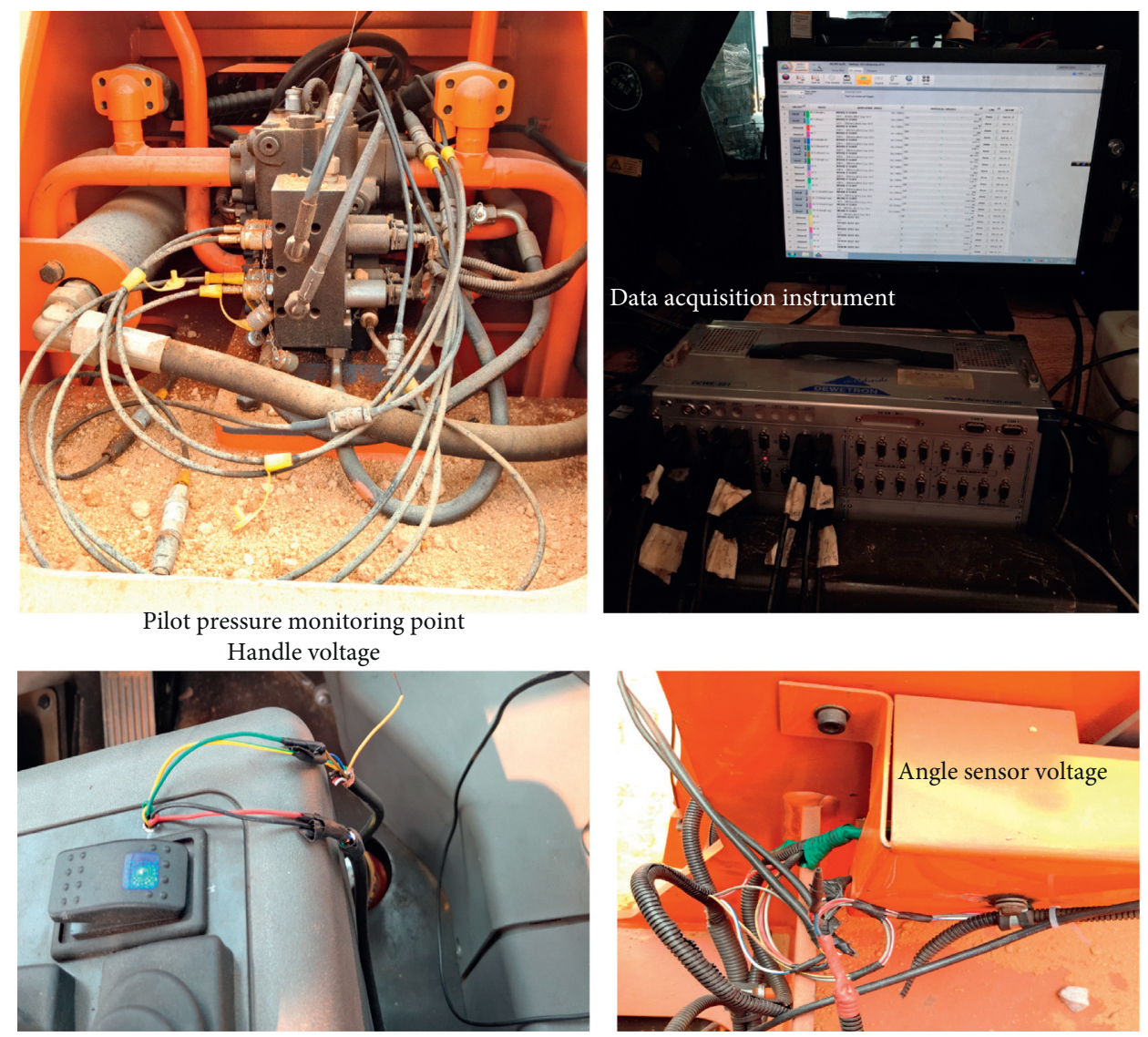

FIgURE 7: Test equipment.

TABle 1: Actual stop angle at memory boom angle of $45^{\circ}$.

\begin{tabular}{lcccccccc}
\hline Engine speed & $800 \mathrm{r} / \mathrm{min}$ & $1000 \mathrm{r} / \mathrm{min}$ & $1200 \mathrm{r} / \mathrm{min}$ & $1400 \mathrm{r} / \mathrm{min}$ & $1600 \mathrm{r} / \mathrm{min}$ & $1800 \mathrm{r} / \mathrm{min}$ & $2000 \mathrm{r} / \mathrm{min}$ & $2200 \mathrm{r} / \mathrm{min}$ \\
\hline Memory angle $45^{\circ}$ & 47.42 & 48.15 & 48.66 & 49.17 & 49.73 & 50.11 & 50.56 & 51.38 \\
\hline
\end{tabular}

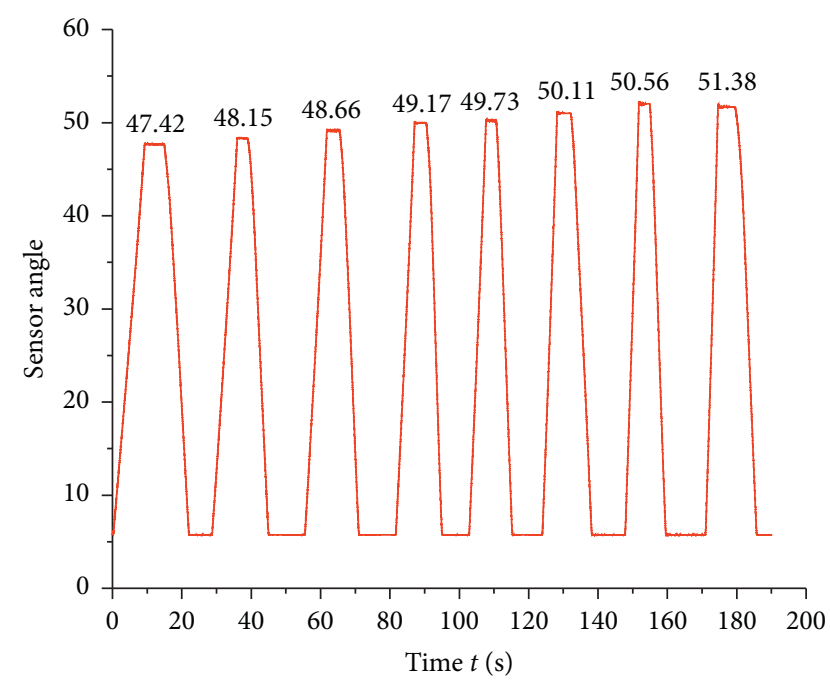

- The actual stop angle curve of the boom

Figure 8: Actual stop angle of the boom.
TABLE 2: Verifying different boom memory angles.

\begin{tabular}{lcccccc}
\hline & $30^{\circ}$ & $35^{\circ}$ & $40^{\circ}$ & $50^{\circ}$ & $60^{\circ}$ & $75^{\circ}$ \\
\hline $800 \mathrm{r} / \mathrm{min}$ & 32.94 & 38.02 & 42.92 & 53.17 & 63.4525 & 79.2525 \\
$1000 \mathrm{r} / \mathrm{min}$ & 33.32 & 39.04 & 43.42 & 54.13 & 64.085 & 80.3725 \\
$1200 \mathrm{r} / \mathrm{min}$ & 34.08 & 39.65 & 43.92 & 54.91 & 65.015 & 81.4425 \\
$1400 \mathrm{r} / \mathrm{min}$ & 34.74 & 40.31 & 44.76 & 55.13 & 65.7425 & 82.4125 \\
$1600 \mathrm{r} / \mathrm{min}$ & 35.42 & 40.87 & 45.31 & 55.92 & 66.4075 & 83.275 \\
$1800 \mathrm{r} / \mathrm{min}$ & 35.88 & 41.03 & 46.04 & 56.34 & 67.175 & 84.17 \\
$2000 \mathrm{r} / \mathrm{min}$ & 36.21 & 41.65 & 46.58 & 57.21 & 68.06 & 85.09 \\
$2200 \mathrm{r} / \mathrm{min}$ & 36.54 & 42.15 & 46.76 & 57.87 & 68.94 & 85.09 \\
\hline
\end{tabular}

the neural network model, and the difference between the actual stop angle and the memory angle is used as the output of the neural network model. The combination of speed and memory angle is used as input vector. There are 56 groups, of which 48 groups are used as the training set and the remaining 8 groups are used as the test set. The number of hidden layer is 16 , and the learning rate is 0.12 . The following steps will analyze the selection of the above parameters. The neural network model prediction data are input to the hydraulic system controller as shown in Figure 10. 
TABLE 3: Verification of the boom memory function at different loads.

\begin{tabular}{lcccccc}
\hline & $3 t \sim 45^{\circ}$ & $5 t \sim 45^{\circ}$ & $3 t \sim 60^{\circ}$ & $5 t \sim 60^{\circ}$ & $3 t \sim 75^{\circ}$ & $5 t \sim 75^{\circ}$ \\
\hline $800 \mathrm{r} / \mathrm{min}$ & 47.67 & 47.42 & 63.27 & 63.08 & 79.01 & 79.64 \\
$1000 \mathrm{r} / \mathrm{min}$ & 48.33 & 48.13 & 63.5 & 63.79 & 85 & 81.92 \\
$1200 \mathrm{r} / \mathrm{min}$ & 49.16 & 48.63 & 65.02 & 64.61 & 82.12 \\
$1400 \mathrm{r} / \mathrm{min}$ & 49.73 & 59.74 & 65.63 & 66.6 & 82.95 \\
$1600 \mathrm{r} / \mathrm{min}$ & 50.26 & 51.36 & 67.23 & 66.85 & 83.52 \\
$1800 \mathrm{r} / \mathrm{min}$ & 51 & 51.58 & 68.63 & 67.61 & 84.62 \\
$2000 \mathrm{r} / \mathrm{min}$ & 51.5 & 51.8 & 69.89 & 68.11 & 85.09 \\
$2200 \mathrm{r} / \mathrm{min}$ & 51.79 & & & 85.09 \\
\hline
\end{tabular}

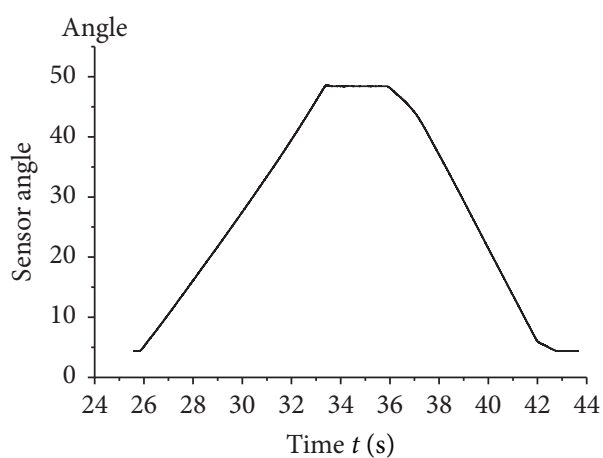

(a)
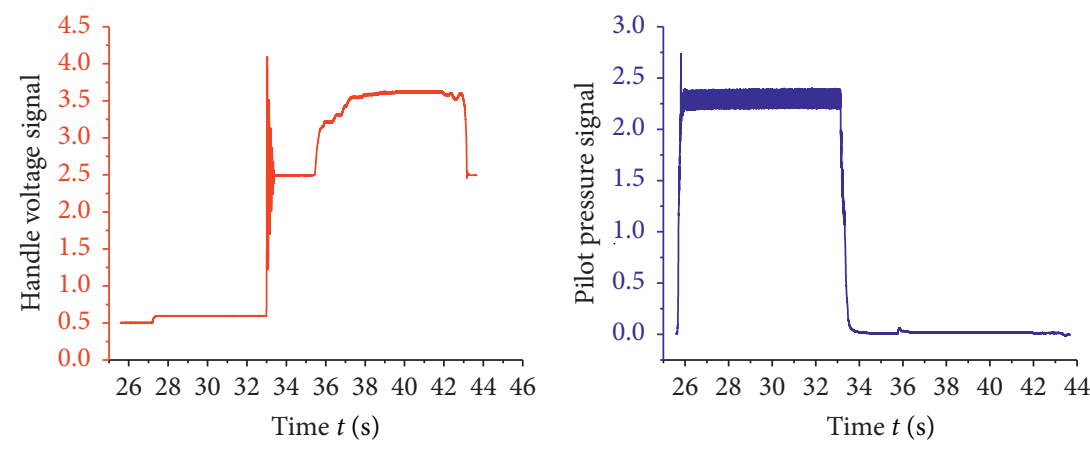

(b) (c)

Figure 9: Verification curve.

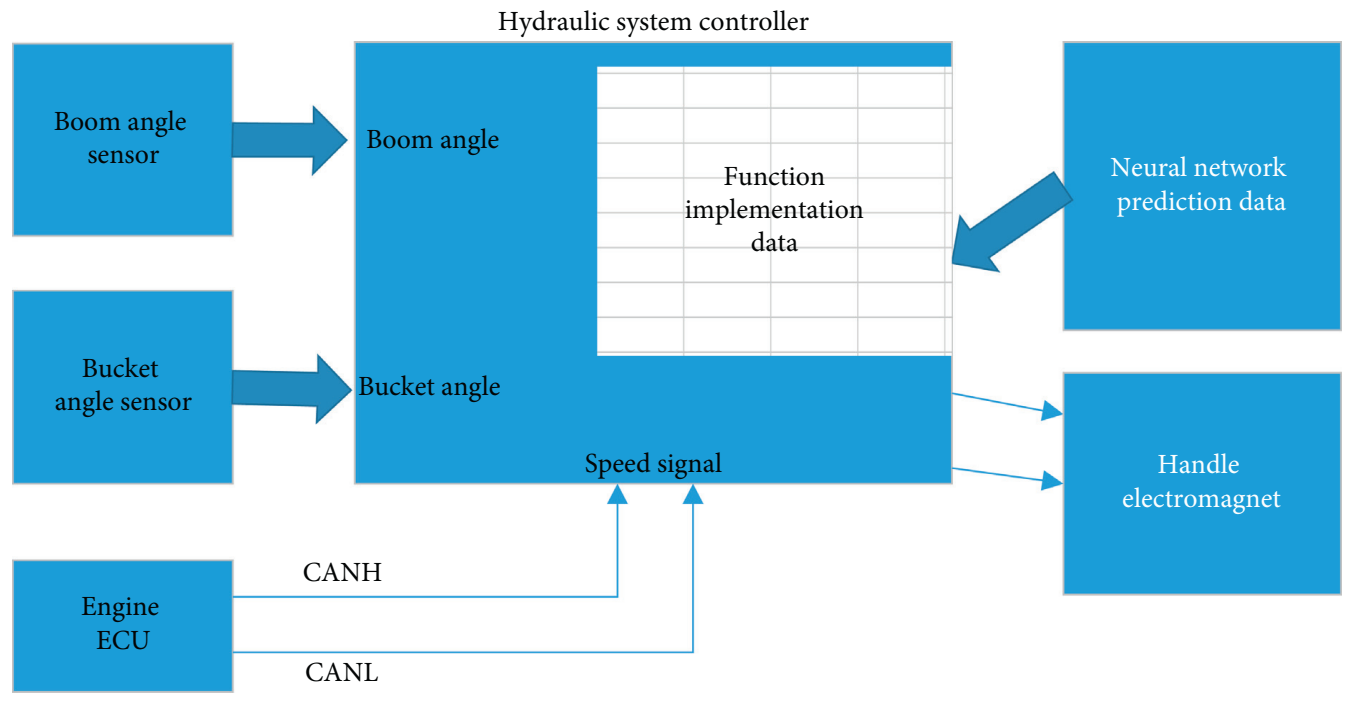

Figure 10: Hydraulic system controller data model.

The error (different speed and memory value) can be predicted by the neural network prediction model, and the above error data are input into the hydraulic system controller in the form of a table. When the driver presses the memory switch, the engine speed can be monitored via the CAN line. According to the above setting conditions, the hydraulic system controller can accurately control the actual stopping angle of the boom by subtracting the error value from the stored angle value. 
A detailed description of the neural network algorithm model is as follows:

Step 1: importing training data [32]. By loading the boom memory test function, the difference between the actual stop angle of the boom and the memory angle of the hydraulic controller can be obtained, as shown in Table 4. Table 4 shows the difference between the boom actual stop angle and the memory angle with different speeds and different memory angles, which is used as the output of the neural network model. The engine speed and the memory values are taken as inputs, while the difference between the memory value and the boom actual value is taken as output.

Step 2: initialization processing. After creating the training set and test set, the data are normalized by using the mapminmax function (normalization function in MATLAB, preprocessing the data) [33].

Step 3: selection of number of hidden nodes and learning rate [34]. The above parameters are determined by calculating the influence of different hidden nodes and learning rates on the training error. Figure 11 shows the effect of different hidden nodes on the training error, while Figure 12 shows the effect of learning rate on the training error. The number of hidden nodes selected is 16 and the selected learning rate is 0.12 .

Step 4: building a neural network [35]. The number of trainings is 1000 , and the accuracy is 0.000000001 ; the prediction is performed after training, while the antinormalization process is also realized. The curve of the training error vs the number of training times is shown in Figure 13.

As can be seen from Figure 13, after the neural network model was trained 25 times, the error value was minimized.

The above operation concludes the construction of the neural network model, while the prediction of data, other than the test, follows, along with the required test and verification. The verification curve is shown in Figure 14, when the memory angle is $45^{\circ}$, while Figure 15 illustrates the same curve, when the memory angle is $60^{\circ}$.

The above test curves show specifically that at memory angle of $45^{\circ}$, the actual stop angle of the boom is $45.29^{\circ}$, at $800 \mathrm{r} / \mathrm{min}$, and $44.90^{\circ}$, at $1100 \mathrm{r} / \mathrm{min}$, while at memory angle of $60^{\circ}$, the actual stop angle of the boom is $60.54^{\circ}$, at $1100 \mathrm{r} / \mathrm{min}$, and $59.32^{\circ}$, at $1900 \mathrm{r} / \mathrm{min}$.

The engine speed is changed during the loader operation. The engine speed test is used to verify the correctness of the neural network model. The obtained test curve is shown in Figure 16.

As can be seen from the Figure 16, the actual boom angle is $59.03^{\circ}$ (the biggest difference from the memory angle) and the maximum error rate is $((60-59.03) / 60) \times 100 \%=1.61 \%$, which meets the requirements of the boom memory function. Considering the measurement error of the sensor, the neural network model can meet the requirements of the boom memory function.
TABle 4: Input and output data.

\begin{tabular}{lccccccc}
\hline & $30^{\circ}$ & $35^{\circ}$ & $40^{\circ}$ & $45^{\circ}$ & $50^{\circ}$ & $60^{\circ}$ & $75^{\circ}$ \\
\hline $800 \mathrm{r} / \mathrm{min}$ & 2.94 & 3.02 & 2.92 & 2.625 & 3.17 & 3.4525 & 4.2525 \\
$1000 \mathrm{r} / \mathrm{min}$ & 3.32 & 4.04 & 3.42 & 3.425 & 4.13 & 4.085 & 5.3725 \\
$1200 \mathrm{r} / \mathrm{min}$ & 4.08 & 4.65 & 3.92 & 4.095 & 4.91 & 5.015 & 6.4425 \\
$1400 \mathrm{r} / \mathrm{min}$ & 4.74 & 5.31 & 4.76 & 4.87 & 5.13 & 5.7425 & 7.4125 \\
$1600 \mathrm{r} / \mathrm{min}$ & 5.42 & 5.87 & 5.31 & 5.4825 & 5.92 & 6.4075 & 8.275 \\
$1800 \mathrm{r} / \mathrm{min}$ & 5.88 & 6.03 & 6.04 & 6.2125 & 6.34 & 7.175 & 9.17 \\
$2000 \mathrm{r} / \mathrm{min}$ & 6.21 & 6.65 & 6.58 & 6.7025 & 7.21 & 8.06 & 10.09 \\
$2200 \mathrm{r} / \mathrm{min}$ & 6.54 & 7.15 & 6.76 & 7.1 & 7.87 & 8.94 & 10.09 \\
\hline
\end{tabular}

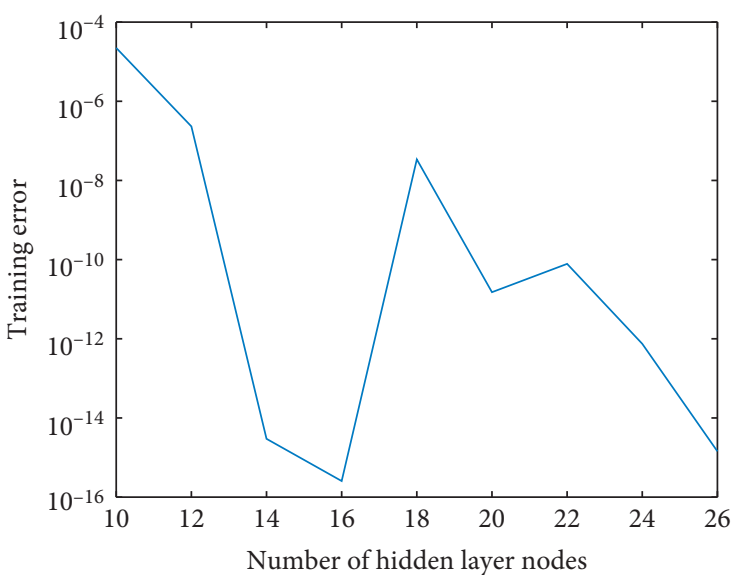

Figure 11: Effect of different hidden nodes on training error.

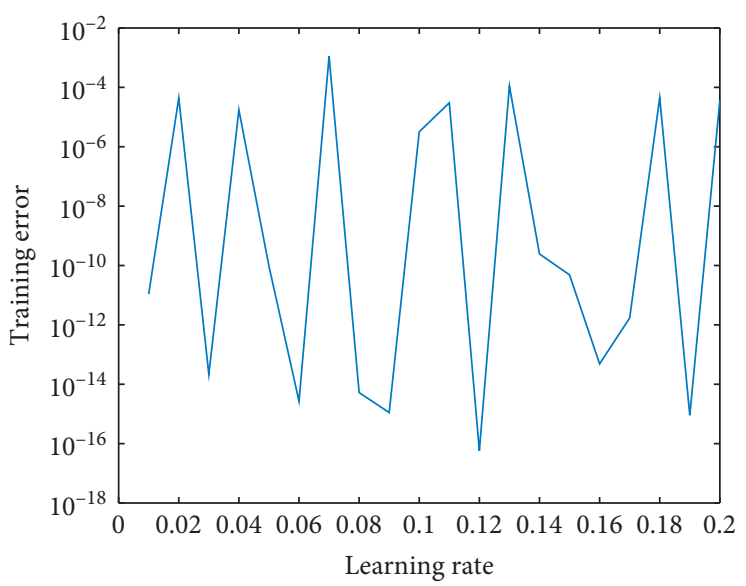

Figure 12: Effect of learning rate on training error.

Taking the engine speed of $800 \mathrm{r} / \mathrm{min}$ and the memory angle of $45^{\circ}$ as an example, when the accurate control is not achieved, the actual stopping angle of the boom can reach $47.42^{\circ}$. However, after the error is predicted by the neural network algorithm, the actual stopping angle of the boom is $45.29^{\circ}$. The angle is reduced by $2.13^{\circ}$, which means that the boom will move less for a distance each time, which saves the energy. 


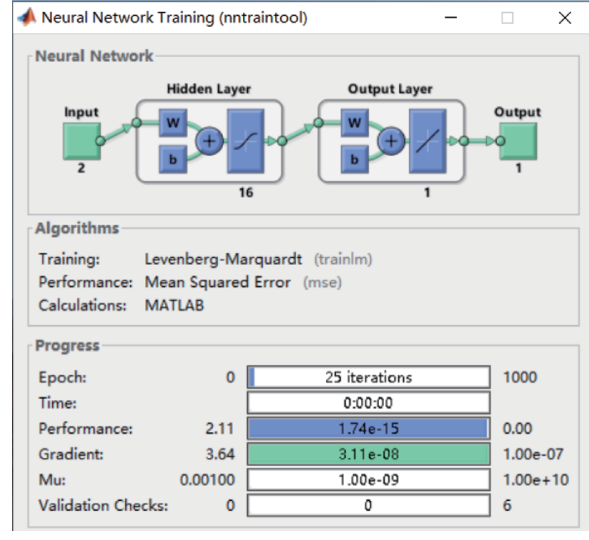

(a)

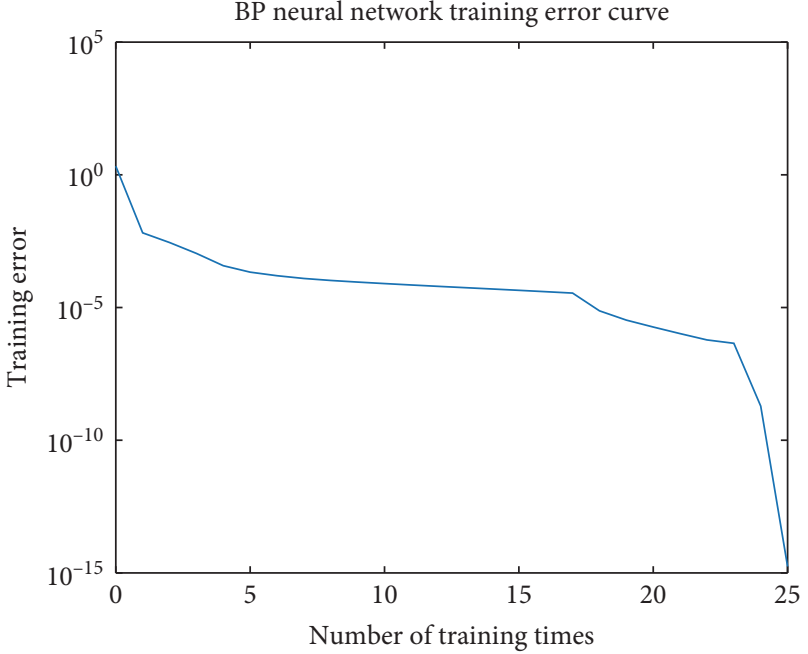

(b)

Figure 13: Training error vs number of training times.

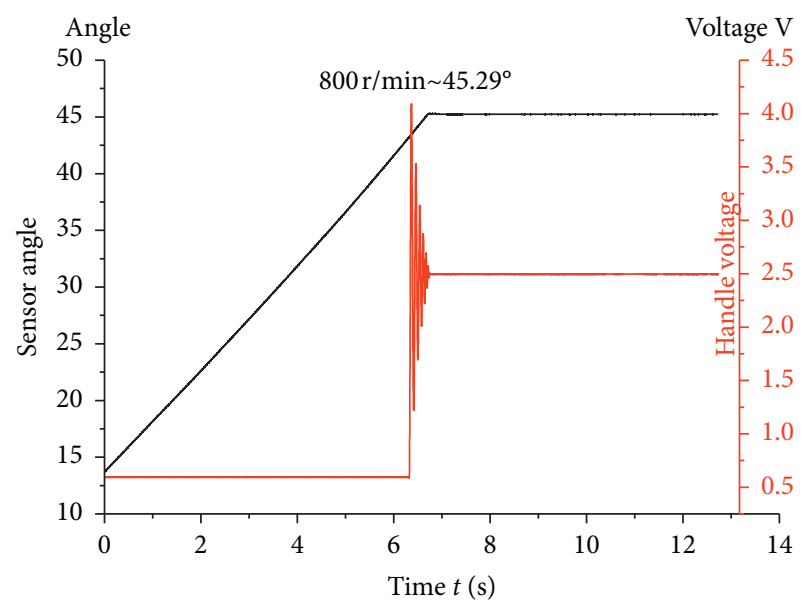

(a)

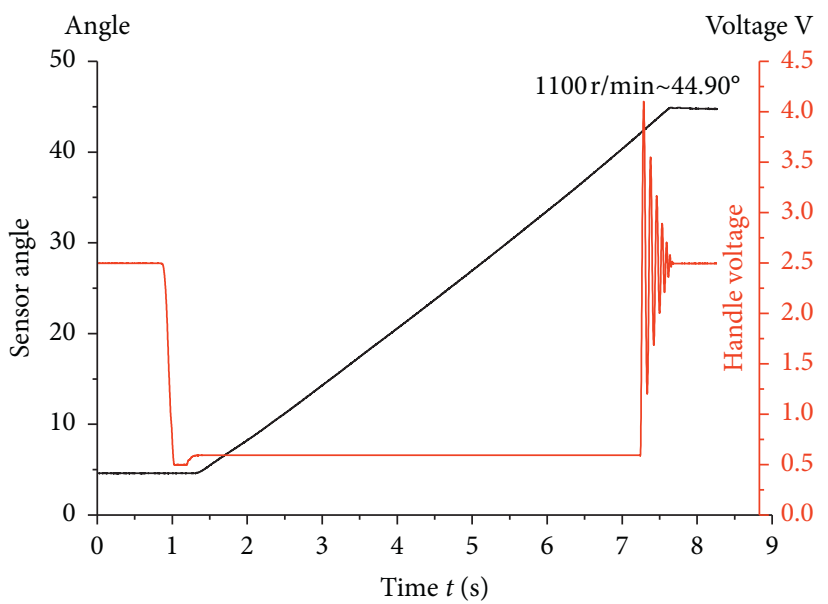

(b)

FIGURE 14: Verification curve at memory angle of $45^{\circ}$.

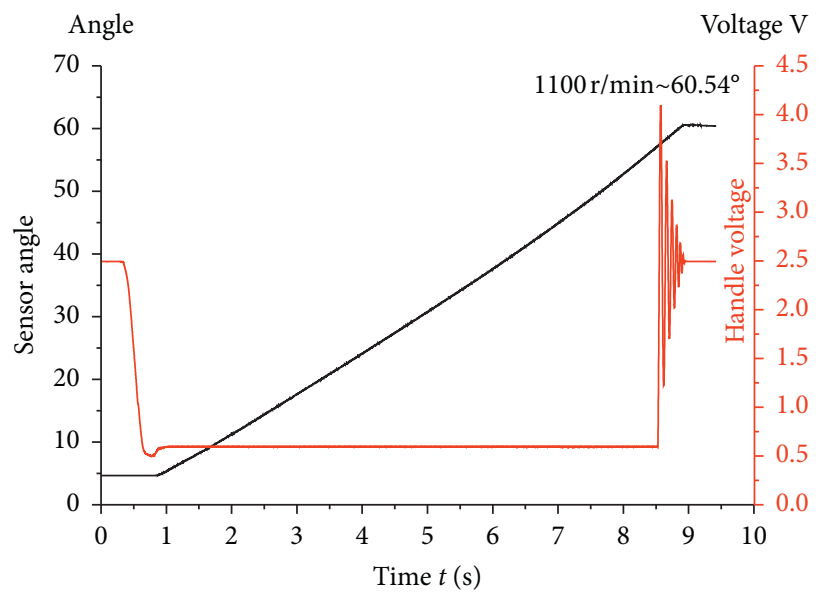

(a)

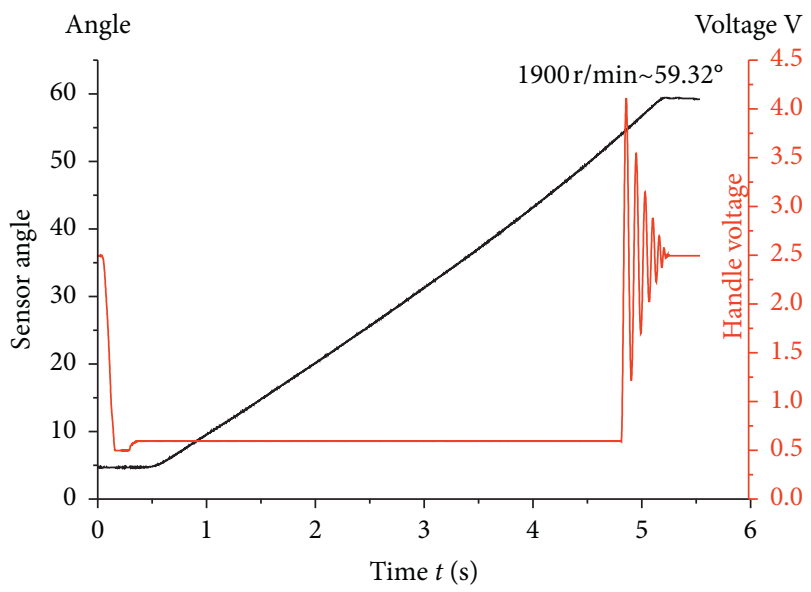

(b)

FIGURE 15: Verification curve at memory angle of $60^{\circ}$. 


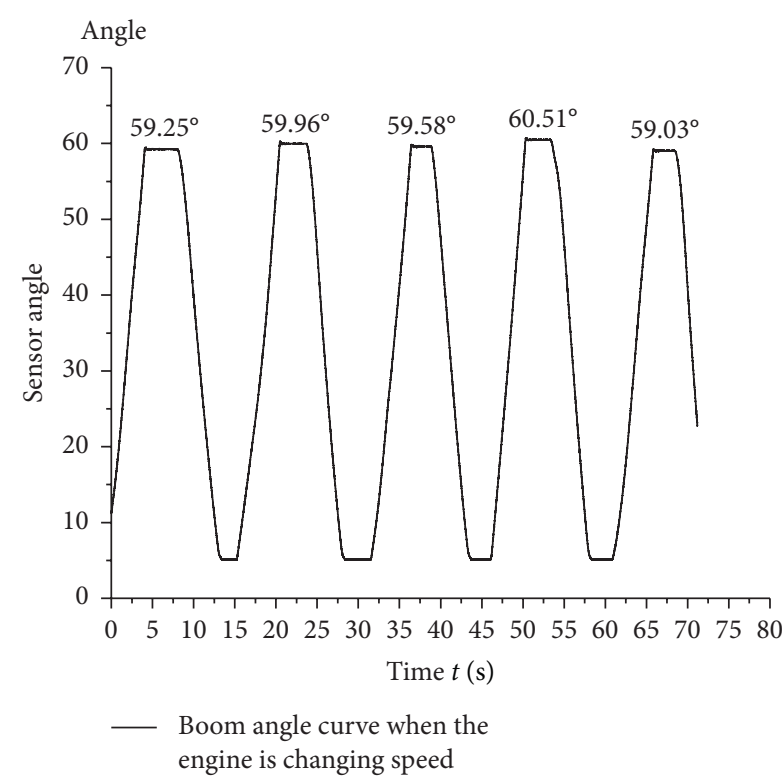

(a)

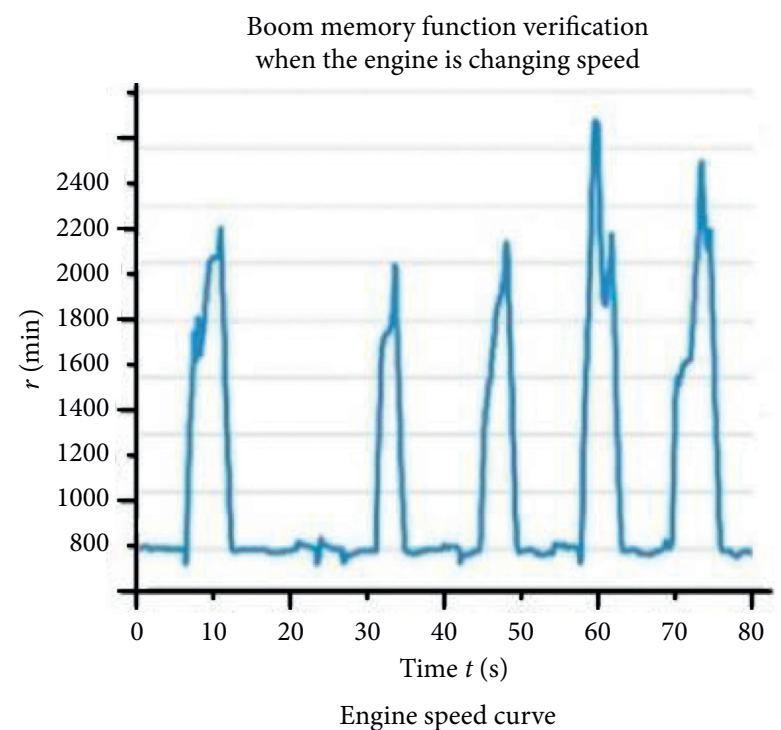

(b)

Figure 16: Verification curve at memory angle of $60^{\circ}$.

\section{Conclusions}

As an innovative point of this paper, the paper firstly proposes the combination of angle sensor and electrohydraulic proportional control technology and initially realizes the boom memory and bucket automatic levelling function of the wheel loader working device. However, subsequent tests have found that the actual stopping angle of the working device is always greater than the working angle of the hydraulic system controller. Then, the neural network algorithm is introduced, and the error value is predicted and input to the hydraulic system controller to achieve precise control of the above functions.

The research content of this paper can be summarized as follows:

(i) A typical V-type operating cycle of the wheel loader is introduced. In order to reduce the driver's operation intensity, the dual-angle sensor is used for real-time monitoring of the boom and bucket angle. The electrohydraulic proportional control technology is used as the carrier to feed the angle sensor signal to the hydraulic system controller. The electro-hydraulic proportional control technology is used as the carrier to feed the angle sensor signal to the hydraulic system controller to realize the boom memory and bucket levelling functions of the wheel loader working device.

(ii) After connecting the data acquisition equipment, the handle voltage, pilot pressure, cylinder pressure, angle sensor, and engine speed signal were collected. The curve analysis showed that the boom memory and the bucket level were not accurately controlled. According to the analysis of the test data, the actual stop angle of the boom increases, as the engine speed rises, while it increases with the memory value, but it is independent of the load. (iii) The data acquisition instrument records real test data, which is used as the raw data of the neural network. After constructing the neural network algorithm model, the load manoeuvring arm memory and the bucket levelling function can be optimized to predict data beyond the test. The above data were imported into the hydraulic system controller, as the boom memory function was again verified. The maximum error rate was $1.61 \%$. The result proves that the optimized model can achieve precise control of the wheel loader intelligent operation.

In the subsequent intelligent operation of the wheel loader, it may be considered to add a radar to measure the height of the truck. The height of the truck is sent to the hydraulic system controller as an input signal and becomes the memory angle of the boom. This eliminates the need to manually store the boom height through the memory switch, which further improves the intelligent operation level of the wheel loader.

\section{Conflicts of Interest}

The authors declare that there are no conflicts of interest regarding the publication of this paper.

\section{Acknowledgments}

This research was funded by the National Key Research and Development Program of China under grant no. 2018YFB2000900.

\section{Supplementary Materials}

Wheel loader data. (Supplementary Materials) 


\section{References}

[1] X. Yan, J. Yang, and L. Quan, "Co-simulation and experiment of wheel loader during operation process," Transactions of the Chinese Society of Agricultural Engineering, vol. 31, no. 16, pp. 102-109, 2015.

[2] X. Wang and S. M. Disney, "Mitigating variance amplification under stochastic lead-time: the proportional control approach," European Journal of Operational Research, vol. 256, no. 1, pp. 151-162, 2017.

[3] Y. Yang, L. Xu, and D. Ren, "Design of electro-hydraulic proportional control system for excavators," Machine Tools and Hydraulics, vol. 40, no. 22, pp. 82-84, 2012.

[4] J. Ye, "Application research of electro-hydraulic proportional control valve in construction machinery," Development \& Innovation of Machinery \&electrical Products, vol. 20, no. 4, pp. 3-5, 2007.

[5] Z. Huang, "Simple electro-proportional control of the A4VSO," Fluid Power Transmission and Control, vol. 4, pp. 26-29, 2016.

[6] F. Zhu, J. Lan, and B. Fu, "Simulation and analysis for electrohydraulic proportional control system of $8 \mathrm{MN}$ hydraulic press," Chinese Hydraulics and Pneumatics, vol. 5, pp. 79-82, 2018.

[7] lifu Yang, "Wheel loader working device electro-hydraulic proportional control system," Construction Machinery, vol. 13 , no. 4, pp. 1-4, 2002.

[8] Y. J. Park, J.-Y. Oh, U.-K. Yun et al., "Design parameter analysis of the proportional control valve for wheel-wheel loader automatic transmission," Journal of the Korean Society for Precision Engineering, vol. 27, no. 5, pp. 27-35, 2010.

[9] X. Bing, R. Ding, and J. Zhang, "Experiment research on individual metering system of mobile machinery based on coordinate control of pump and valves," Journal of Zhejiang University (Engineering Science), vol. 49, no. 1, pp. 93-101, 2015.

[10] K. Yongling, "Research and application of electro-hydraulic proportional control system based on PWM technology," Coal Mine Electromechanical, vol. 2, no. 3, pp. 28-32, 2017.

[11] Y. Zhang, L. Wang, and Y. Gai, "Research on valve-controlled cylinder experimental system based on electro-hydraulic proportional technology," Disciplines Exploration, vol. 35, no. 5, pp. 28-30, 2018.

[12] J. Fang, Y. Zhang, and Y. Fang, "Study of the control strategy of an electro-hydraulic control system," Machine Tools \& Hydraulics, vol. 36, no. 2, pp. 114-116, 2003.

[13] D. Liu, "Rotational speed and simulation of wind turbine based on BP Neural network controller," Instrument Technique and Sensor, vol. 6, pp. 13-16, 2018.

[14] S. Huang, Z. Chen, Y. Jiao et al., "Fuzzy-neural networks PID control based on DSP for hydraulic servo system," Chinese Hydraulics and Pneumatics, vol. 9, pp. 15-25, 2015.

[15] H. Shan and G. Shen, "Damping neural network control of air suspension for mine vehicle," Coal Mine Machinery, vol. 35, no. 5, pp. 75-77, 2014.

[16] Y.-H. Lee and R. Kopp, "Application of Fuzzy Control for a hydraulic forging machine," Fuzzy Sets and Systems, vol. 118, no. 1, pp. 99-108, 2001.

[17] A. Ferhat bayram, "Application of an artificial neural network model to a na-k geothermometer," Volcanology and Geothermal Research, vol. 66, no. 112, pp. 75-81, 2008.

[18] J. Wongsaroj, K. Soga, and R. J. Mair, "Modeling of long-term ground response to tunnelling," Journal of Geotechnical and Environmental Engineering, vol. 57, no. 10, pp. 75-90, 2007.

[19] H. Xu and Y. Mai, "Adaptive PID control of hydraulic material testing machine system based on neural network,"
Journal of Mechanical \& Electrical Engineering, vol. 35, no. 4, pp. 375-379, 2018.

[20] H. Ni, S. Wang, S. wang et al., "Improvement of hydraulic control system based on BP neural network PID control," Forging \& Stamping Technology, vol. 40, no. 11, pp. 61-70, 2015.

[21] B. Gao and W. Han, "Neural network model reference decoupling control for single leg joint of hydraulic quadruped robot," Assembly Automation, vol. 38, no. 4, pp. 465-475, 2018.

[22] H. Huang, W. Gong, D. Zhao et al., "Wheel loader working device electronic positioning system," Construction Machinery, vol. 20, no. 4, pp. 26-32, 2002.

[23] T. Lou, H. Ding, J. Dong et al., "Design and simulation analysis of electro-hydraulic proportional closed loop drive systems in closed loop control o for coal mine hydraulic winch," Chinese Hydraulics \& Pneumatics, vol. 6, pp. 63-68, 2019.

[24] N. Zhang, "Hydraulic leveling technology for electro-hydraulic proportional control based on fuzzy PID," Shanxi Electronic Technology, vol. 4, pp. 39-42, 2015.

[25] L. Xu, W. Li, C. Qin et al., "Experimental study on distribution characteristics of loader engine output power," Machinery Design \& Manufacture, vol. 7, pp. 74-77, 2018.

[26] Z. Wang and S. Qin, "Analysis of dynamic characteristics of hydraulic torque converter applied to wheel loader," Journal of South china University of Technology, vol. 44, no. 7, pp. 41-46, 2016.

[27] L. Xu, R. Ge, and L. Chang, "Acquisition method of load time course of wheel loader hydraulic system under typical operating conditions," Transactions of the Chinese Society of Agricultural Engineering, vol. 28, no. 6, pp. 57-62, 2012.

[28] J. Zhang, M. Zeng, and W. Liu, "Control strategy of cylinders synchronization motion of tensioner based on PID neural network integrated controller," Machine Tool \& Hydraulics, vol. 38, no. 7, pp. 7-10, 2010.

[29] H. Mu, J. Han, and M. Li, "Research on the improved particle swarm optimization algorithm in the coal mill PID neural network control," Journal of Jinling Institute of Technology, vol. 35, no. 2, pp. 16-20, 2019.

[30] Q. Li and F. Ding, "Simulation and experimental study on stroke force characteristics of proportional electromagnet," Transactions of the Chinese Society of Agricultural Engineering, vol. 15, no. 2, pp. 104-107, 2005.

[31] H. Pan, B. Li, and Y. Lei, "Method for evaluating the correct rate of neural network model prediction results," Industrial Building, vol. 14, no. 6, pp. 37-39, 2007.

[32] X. Luo and L. Li, "The research on communication base station's air-conditioner system fuzzy neural network control," Journal of Dezhou University, vol. 2, pp. 57-61, 2015.

[33] W. He and Y. Dong, "Adaptive fuzzy neural network control for a constrained robot using impedance learning," IEEE Transactions on Neural Networks and Learning Systems, vol. 29, no. 4, pp. 1174-1186, 2018.

[34] Y. Hu and B. Si, "A reinforcement learning neural network for robotic manipulator control," Neural Computation, vol. 30, no. 5, pp. 13-22, 2018.

[35] B. G. Kumar, S. R. Shankapal, A. S. Ravindran et al., "Fuzzy logic and neural network based induction control in a diesel engine," Advances in Intelligent Systems and Computing, vol. 270, pp. 77-91, 2014. 